ARTICLE

Jennifer Thomas and Joanne Evans Office for National Statistics

\title{
There's more to life than GDP but how can we measure it?
}

\section{Introduction}

\section{SUMMARY}

The report by the Commission on the Measurement of Economic Performance and Social Progress, led by Professors Stiglitz, Sen and Fitoussi, is widely seen as setting the agenda for measuring societal wellbeing, going beyond the established headline measure of economic performance, Gross Domestic Product (GDP).

In the 2010 Budget Report, it was noted (Box 1.2, page 10) that 'there is widespread acknowledgement that GDP is not the ideal measure of wellbeing'. The Budget Report continues 'the Government is committed to developing broader indicators of wellbeing and sustainability with work currently under way to review how the Stiglitz, Sen and Fitoussi report should affect the sustainability and wellbeing indicators collected by Defra (Department for Environment, Food and Rural Affairs), and with the Office for National Statistics (ONS) and the Cabinet Office leading work on taking forward the report's agenda across the UK.'

This article identifies relevant Government Statistical Service outputs and initiatives that support this broader societal wellbeing agenda. It follows the structure of the Stiglitz, Sen and Fitoussi report, addressing classical GDP issues, quality of life and sustainable development and the environment. All three are interconnected and together provide the fullest picture of wellbeing. Measuring how these change over time gives the fullest picture of progress. The article concludes with an outline of next steps.
-

here is increasing interest in

wider measures of economic

performance and social progress, including the impact on the environment and sustainability. The 2010 Budget Report notes (see Box 1.2, p. 10 in HM Treasury 2010) that 'there is widespread acknowledgement that Gross Domestic Product (GDP) is not the ideal measure of wellbeing' ${ }^{1}$ and that 'the Government is committed to developing broader indicators of wellbeing and sustainability'.

This builds on the Conservative party commitment in their 2010 manifesto, 'Invitation to join the Government of Britain', to develop 'a measure of wellbeing that encapsulates the social value of state action' (p.38) and earlier calls for general wellbeing measures. (For example, one of the recommendations of the Conservative Quality of Life Policy Group's 1997 report $^{2}$ calls for a triad of economic, environmental and social indicators, as a framework for policy making that focuses on general wellbeing, not just on GDP). In February 2010, David Cameron addressed a

Technology-Entertainment-Design (TED) conference on the next age of government ${ }^{3}$. He ended his presentation by referring to the Robert Kennedy speech about why GDP captures so little and said this is 'a dream more easily realisable now than 40 years ago'.

At an international level, the European Commission's 'GDP and beyond' project ${ }^{4}$ and the Organisation for Economic Cooperation and Development (OECD)'s global project on 'measuring the progress of societies' ${ }^{\prime 5}$ have been looking at this subject for some time and measuring societal progress was the theme for the second OECD World Forum on Statistics, Knowledge and Policy in 2007. From this forum emerged the 'Istanbul declaration', which called for the production of 'highquality facts-based information that can be used by all of society to form a shared view of societal wellbeing and its evolution over time.'

More recently, the need to look beyond GDP when evaluating societal progress was exemplified in a report in 2009 commissioned by President Sarkozy - the Commission on the Measurement of Economic Performance and Social Progress ${ }^{7}$ (referred to as the Stiglitz Commission from this point forward after the chair Joseph Stiglitz of Columbia University). The Stiglitz Commission highlighted that both committing certain types of crime and buying petrol can lead to an increase in GDP but not lead to an increase in welfare, exemplifying why GDP is not an overall measure of progress. National statistical systems need to widen the focus from measuring market production towards more complete measures of societal wellbeing, including quality of life and sustainability.

The Stiglitz Commission and the economic downturn provide the stimulus to develop the measurement of wellbeing in the UK. Leading commentators and politicians are rethinking the emphasis on economic growth. From this and 
other discussions should emerge a clearer specification for wider measures.

The framework and recommendations outlined by the Stiglitz Commission provide a firm foundation for the Government Statistical Service (GSS), the Government Economic Service (GES) and the Government Social Research Service (GSR), along with policy makers, to develop ways to measure social progress in the UK. ONS's general approach recognises that there are many existing statistical products to help meet the demand for wider measures. What is missing is a sense of coherence and how various constituent parts might add up to provide a more complete picture. This article summarises work across the GSS on the wider Stiglitz Commission agenda, which here is called measuring societal wellbeing (shorthand for measuring economic performance, social progress and environmental and sustainability issues).

\section{Current status}

Despite the renewed emphasis on wellbeing, this is not a new concept in the UK. There has been a long standing policy interest in alternative measures, for example HM Treasury has wellbeing listed in their Departmental Strategic Objectives ${ }^{8}$ and the UK 2005 sustainable development strategy 'Securing the Future' revealed concern that government policy was targeted too much on increasing GDP and neglected wider Quality of Life issues ${ }^{9}$ which predate the Stiglitz Commission report. Even earlier was the social indicator movement, from which outputs such as the UK Social Trends ${ }^{10}$ were devised to present social measures alongside economic statistics (and, in the case of Social Trends, published annually for the past 40 years). Wellbeing has been one of ONS's analytical priorities ${ }^{11}$ since 2007, when Allin (2007) summarised a number of pathways to measure wellbeing.

The UK has a wealth of relevant statistical data, analyses and outputs, but this is not presented or recognised as helping to understand societal wellbeing. For example, the National Accounts provide measures such as Net National Product (NNP) alongside GDP, but these are not highlighted or commented on as much as GDP. ONS has published a Household Satellite Account and regularly publishes Environmental Satellite Accounts. There are annual analyses of the distribution of household incomes ${ }^{12}$ and a new report on wealth in Great Britain was published at the end of $2009^{13}$.

The ONS website holds guidance on how to define and measure social capital.
There is an established set of Sustainable Development Indicators for the UK produced by Defra ${ }^{14}$ and established measures of personal wellbeing, which have been included since 2007 . The UK is also breaking new ground in developing statistics to monitor equality in society, including through an Equality Measurement Framework ${ }^{15}$, and to measure the outputs of government activity as well as the inputs. All of these contribute to the understanding of societal wellbeing.

There are also developments outside the Government Statistical Service (GSS). The Young Foundation is engaged with wellbeing initiatives at the local level, and has published guidance on local indicators ${ }^{16}$. The New Economics Foundation (NEF) has published a Happy Planet Index ${ }^{17}$ and the National Accounts of Wellbeing ${ }^{18}$. There is also strong interest in happiness as an input to policy.

This list is not exhaustive but illustrates that there is much useful information already available to help measure societal wellbeing in the UK. What is not known is what it all adds up to. It will be seen that there are other developments - new sources, research and analysis - that could be made in light of the Stiglitz Commission report, if resources are available.

\section{A framework}

The Stiglitz Commission report is a useful starting point due to its widely accepted status and international recognition. As a framework ONS has adopted the three strands of the Stiglitz Commission report as the cornerstones:

- working through classical GDP issues for a fuller understanding of the economy, particularly the household sector

- measuring quality of life for better understanding of society, and

- tracking sustainable development and the environment as the third strand

All of these interact with one another.

The rest of this article will be structured around these three headings, identifying current work and potential developments within each area.

\section{Classical GDP issues}

National Accounts are a structured way of defining, presenting and measuring economic production. The accounts have statistical rigour, are internationally agreed and are underpinned by a firm conceptual basis. They do not cover, and do not claim to cover, all of the dimensions relevant to societal wellbeing.

The Stiglitz Commission report (p.11) suggested that 'before going beyond GDP and tackling the more difficult task of measuring wellbeing it is worth asking where existing measures of economic performance need improving.'

GDP is the most widely used measure of National Income but has often been criticised for being a poor indicator of a society's wellbeing ${ }^{19}$, on the grounds that it does not measure some activities inside the production boundary well and excludes some welfare determinants outside the production boundary (see Allin (2007) for a discussion of these criticisms). As such, the Stiglitz Commission report indicates that alternative components of the National Accounts may be better measures of economic progress.

\section{Current activities}

ONS undertakes a number of activities that address the issues previously identified. For example, many of the alternative measures of National Income discussed in the Stiglitz Commission report are already published in the Blue Book ${ }^{20}$. ONS supplements National Accounts with income and consumption analyses (for example, quarterly Consumer Trend ${ }^{21}$ ) and produces a wide range of information on income and wealth of households and individuals ${ }^{22}$. ONS regularly publishes articles concerning households and the labour market using data from a wide variety of household surveys and the Wealth and Assets Survey published results for the first time in December $2009^{13}$. Further, ONS produces estimates of public service output ${ }^{23}$ and has experience in producing environmental ${ }^{24}$, and household ${ }^{25}$ satellite accounts.

ONS's annual articles on the distribution of income ${ }^{12}$ examine how taxes and benefits redistribute income between various groups of households in the UK. The work shows where different types of households and individuals are in the income distribution and looks at the changing levels of income inequality over time given a more accurate reflection of a household's disposable income.

ONS is developing measures of stocks which are not presented in the National Accounts, such as human capital, and exploring interest in other stocks, such as cultural capital, that have been pursued in other disciplines and policy areas. Experimental estimates of the stock of human capital will be published in the autumn.

The Stiglitz Commission report defined 
a number of improvements that could be made within the existing National Accounts frameworks. These include highlighting other headline measures from the National Accounts, in addition to GDP such as Gross National Product (GNP) and Net National Product (NNP). This is investigated further in Chiripanhura (2010), which presents, explains and explores the wellbeing implications of other National Accounts aggregates.

\section{Potential developments}

These aggregates are economy-wide measures that say little about the distribution of income, and using median measures rather than the mean, to give a more reliable indication of income of the 'average' person as well as the extent of concentrations of high and low incomes. The Stiglitz Commission report also highlighted the necessity of expanding our measures of economic progress to include wealth and consumption. The National Accounts already contain several measures of household wealth and these are being improved. Additional work will be undertaken to establish more clearly the links between all of the forementioned products and the wellbeing agenda.

Table 1 matches the Stiglitz Commission's Classical GDP recommendations with current activities and the potential developments proposed in this article.

\section{Quality of life}

The second of the three categories addressed in the Stiglitz Commission report is quality of life. It highlights that economic resources are not all that matters for human wellbeing. The development of indicators for all determinants of wellbeing or the bringing together of existing information to provide a more complete picture is needed. The report stated that, 'quality of life is a broader concept than economic production and living standards. It includes the full range of factors that influences what we value in living, reaching beyond its material side.' (Stiglitz Commission report, p. 41).

More specifically, the Stiglitz Commission report indicated the importance of statistical offices providing the objective and subjective information needed to aggregate across quality of life dimensions. It did so highlighting the challenges such as a lack of indicators in a number of domains, in addition to the importance of linking measures across domains and to equalities work.

In the UK, there have been a number of initiatives concerned with measuring quality of life by ONS, other Government departments such as Defra, devolved governments, regional statisticians, local governments and think tanks. These have produced a number of relevant approaches and outputs such as the Young Foundation guidance on wellbeing at a local level ${ }^{16}$ and NEF's Happy Planet Index ${ }^{17}$ and the National Accounts of Wellbeing ${ }^{18}$. ONS has developed guidance on how to define and measure social capital ${ }^{26}$. The UK is also a world leader in developing equality statistics to monitor inequality in society via the Equality Measurement Framework project ${ }^{15}$ which overlaps considerably with wellbeing developments.

In addition, the UK has an extensive range of social indicators regularly reported in Social Trends and included in the OECD

Table 1

\section{The Stiglitz Commission's Classical GDP recommendations, existing ONS work and potential areas for development}

Stiglitz Commission recommendation

1. When evaluating material wellbeing, look at income and consumption rather than production Existing ONS work and potential areas for development

\section{Existing work:}

ONS supplements summary National Accounts with income and consumption analyses (quarterly Consumer Trends publication). There is a programme of work improving the measurement of government provided services to help provide a fuller picture of peoples' living standards, including healthcare and education.

ONS has published analyses that present, explain and explore other well established indicators in the National Accounts (such as Net National Product, Gross National Product and Net Domestic Product) alongside Gross Domestic Product.

Areas for development:

Explore what other outputs are available for the UK on the Classical GDP issues presented by the Stiglitz Commission.

Explore potential for other wellbeing related issues to be investigated as part of wider work on measuring the value added by pubic services.

2. Emphasise the household perspective Existing work:

ONS has a rich source of household surveys including all (adult) members of the household, ONS publishes regular analyses of households and the labour market.

Areas for development:

Develop the links between the household survey analyses and the National Accounts outputs.

3. Consider income and consumption Existing work:

jointly with wealth

ONS undertakes a range of analyses on wealth including the Social Trends chapters on Income, Wealth and Expenditure and the Wealth in Great Britain report published in December 2009, based on the Wealth \& Assets Survey (see Daffin 2010).

Areas for development:

Develop Wealth Accounts to provide a comprehensive picture of wealth and indebtedness among the UK population.

Improve the links between income, consumption and wealth outputs and the National Accounts outputs.

4. Give more prominence to the Existing work:

distribution of income, consumption and wealth

ONS publishes an annual article on distribution of income, and how taxes and benefits redistribute income (see Barnard 2010).

Areas for development:

Ensure ONS outputs on income, wealth, expenditure and consumption use a variety of measures of central tendency (mean and median) in addition to focussing on distributions.

An article on median income is due to be published in autumn 2010.

5. Broaden income measures to nonExisting work:

ONS published experimental Household Satellite Accounts using data from the UK Time Use Survey. There is a programme of work improving the measurement of government provided services to help provide a fuller picture of peoples' living standards, including healthcare and education. Areas for development:

Continue with the existing development work on household, human capital, and environmental satellite accounts ${ }^{1}$. 


\section{Box 1}

\section{Domains to measure quality of life}

1. Material living standards

2. Health

3. Education

4. Personal activities including work

5. Political voice and governance

6. Social connections and relationships

7. Environmental conditions

8. Insecurity (economic and physical)

9. Overall life satisfaction

\section{Box 2}

\section{Domains to measure quality of life}

\section{Figure A}

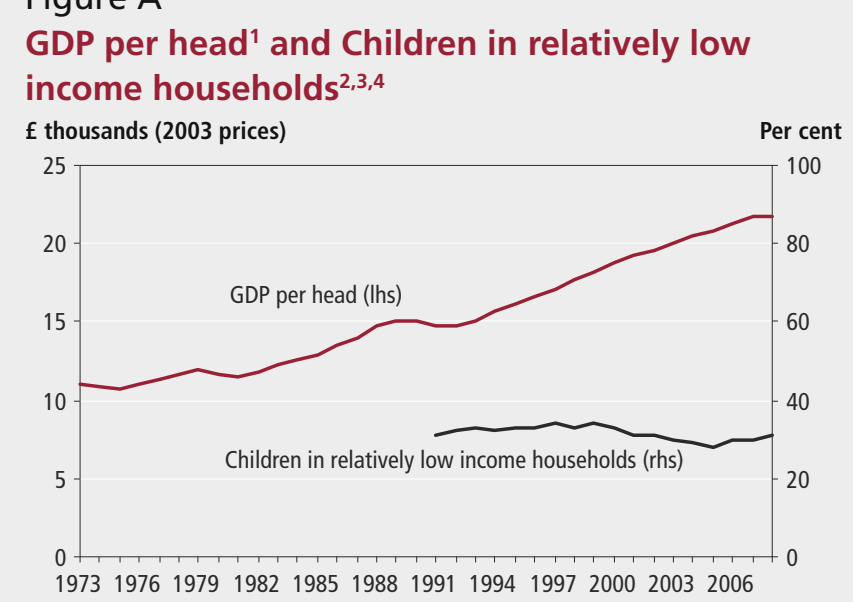

\section{Notes:}

1 United Kingdom. 1 United Kingdom.
2 United Kingdom prior to 1994-95,
Great Britain from 1994-95.

3 Based on 60 per cent of median

income relative income thresholds.

4 Data are for financial years.

\section{Figure C}

\section{GDP per head ${ }^{1}$ and all BSC crime $^{2,3}$}

$f$ thousands (2003 prices)

Source: ONS Family Expenditure Survey (1979 to 1993-94, UK) and Family Resources Survey (1994-95 to 2007-08, GB)

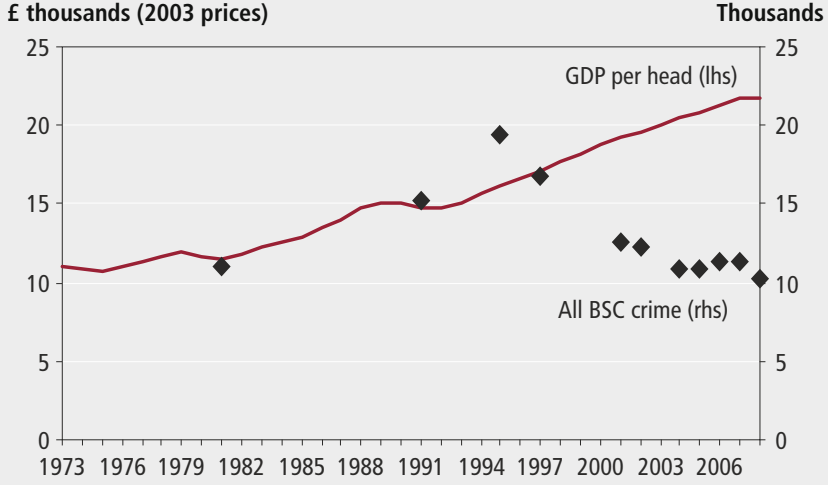

\section{Notes:}

Source: ONS, Home Office

1 United Kingdom.

2 British Crime Survey, England and Wales.

3 From 2001/02 data are for financial years.

\section{Figure $B$}

\section{GDP per head ${ }^{1}$ and those volunteering as a} percentage of all people $e^{2,3}$

$f$ thousands (2003 prices)

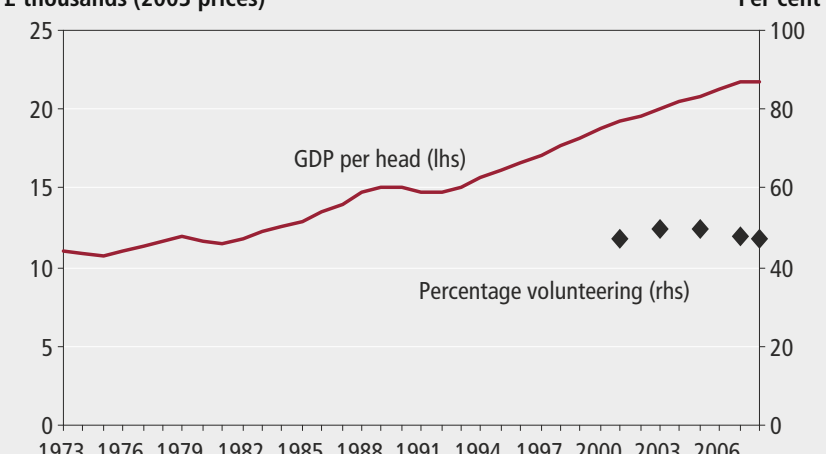

197319761979198219851988199119941997200020032006

Notes:

Source: ONS, Home Office

1 United Kingdom

2 England and Wales.

3 Data are for financial years.
Figure D

GDP per head ${ }^{1}$ and Healthy Life Expectancy (HLE) at birth ${ }^{2,3}$

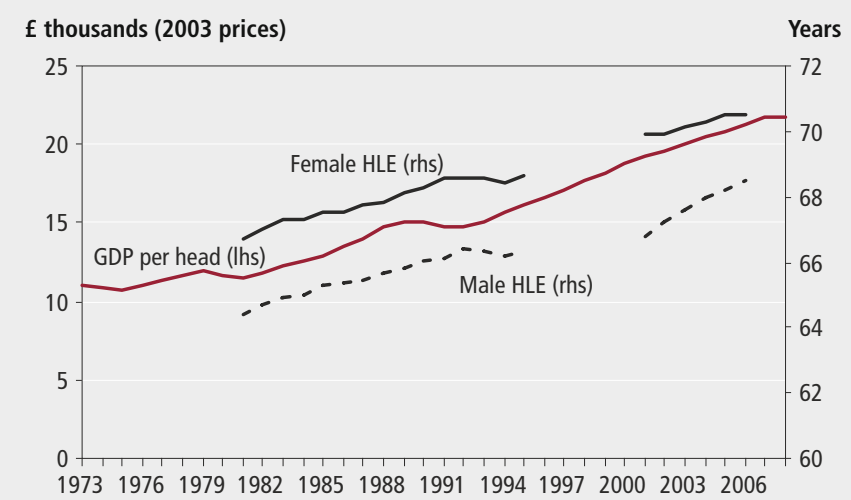

Notes:

Source: ONS

1 United Kingdom

2 Great Britain.

3 HLE estimates are based on a three-year moving average plotted on the central year. Data for 1996, 1998 and 2000 are unavailable because the General Household Survey was not carried out in 1997 or 1999.
Social Indicator Set. A large number of Defra's Sustainable Development Indicators ${ }^{14}$ are social indicators and the set includes wellbeing measures. ONS has made some headway in determining the extent of societal wellbeing domain and indictor coverage across the UK by undertaking a high level audit of available indicators and identifying suitable datasets.

To structure the work ONS is using the domains identified in Chapter 2 of the Stiglitz Commission report and taking overall subjective wellbeing, or self evaluated measures of satisfaction with life, as a further domain. Box 1 shows the 
nine domains that ONS has used to help structure actions and plans for the better measurement of quality of life.

Within this framework the first eight domains relate to predominantly objective measures (observable facts). They cover social, environmental and economic resources that are often measured using existing data sources. There is also scope to include subjective measures (such as fear of crime, alongside measures of crime). The ninth wellbeing domain aims to capture people's thoughts and feelings about their life overall.

\section{Objective measures}

Box 2 shows a small selection of all the available indicators just to give a flavour of the breadth of indicators produced across the GSS. The charts show that social indicators generally move differently to GDP per head over a length of time. The charts look at wider measures of social progress such as crime, healthy life expectancy and children living in poverty. They demonstrate that while GDP per head has been increasing the other measures show a more mixed story (although, interestingly, healthy life expectancy appears to track GDP per head fairly closely).

The challenge remains of how to summarise overall wellbeing using a set of indicators like this - what does it all add up to? That assumes that it makes sense to measure wellbeing (and changes in wellbeing, or progress) overall. It also leads to the question of whether a single index is required and, if so, how the various components within it would be weighted together. All of this needs further debate.

The analysis from the audit also echoes the findings in the Stiglitz Commission report that call for some improvements to be made across the domains. The health and insecurity domains have the best indicator coverage, while social connections and political voice need the most development work. Some domains are already on track for developments via different programmes of work. For example the Equality and Human Rights Commission is exploring measures of participation, influence and voice, and good relations.

Additional developments are also required within the personal activities including work domain. The Stiglitz Commission report suggests this includes paid work, unpaid work, commuting and leisure time (quantity and quality) and housing. The UK has robust employment and housing data. In addition, results from the Department for Culture Media and
Sport (DCMS) Taking Part Survey ${ }^{27}$ and from the earlier UK Time Use Surveys $(2000-03)^{28}$ are still being analysed. Time use and participation patterns generally change slowly, at least in terms of the broad categories of activities.

There are no current plans to conduct another Time Use survey in the UK, although other countries have done so, for example following the European model of harmonised time use surveys. However, more could be done to learn about and disseminate recent research into time, utility and national product (see Gershunny 2008, 2009) and to raise the profile of this work with policy makers (Krueger et al 2009). The Centre for Time Use Research ${ }^{29}$ is undertaking work in this area. Prompted by the US work referenced here, one potential use is as a way of weighting the components of wellbeing into a summary index. The weights would reflect how people value the different aspects of wellbeing, ideally as a combination of the time they spend on, and the satisfaction they get from, each dimension.

\section{Subjective measures}

The Stiglitz Commission report suggests that statistical offices should incorporate questions to capture people's life evaluations, hedonic experiences and priorities into surveys. The point is that by asking people for their views and life experiences, the issue of paternalism, in the sense of defining what wellbeing is without consultation, is largely avoided. Much recent research indicates that measures of subjective wellbeing tend to correlate well with other people's views, behavioural data, brain activity and objective characteristics such as unemployment (see Layard 2005 for a useful review). It is outside the scope of this article, but it is noted there are a number of policy areas in which subjective wellbeing is being recognised.

Over the last few years life satisfaction questions, through work led by Defra, have been included in several Government surveys in the UK, for example the Citizenship Survey, the British Crime Survey and Defra's Survey of Public Attitudes and Behaviours towards the Environment ${ }^{14}$.

Figure 1 shows that the most commonly used measure of life satisfaction moves very differently to GDP. While GDP has gradually increased over the last 33 years, life satisfaction has stayed relatively stable with around 86 per cent of people being satisfied with their lives in any year.

However, there are a number of limitations in using subjective measures; these include the unavoidable use of bounded measures, the research finding that most people's subjective wellbeing tends to fluctuate around a 'set point', and difficulties determining cause and effect. For example, does volunteering make people happy or do happy people engage in volunteering?

Nonetheless, an encouraging literature is building towards the conclusion that subjective wellbeing is a valid construct that can be measured reliably. The evidence suggests that various social and economic factors affect self-reported quality of life so it should be possible to influence subjective wellbeing via policy. Figure 2, for example, reproduces some recent data collected by Defra indicating that self-reported life satisfaction differs according to socioeconomic status. It appears that higher percentages of people in higher paid or intermediate jobs rate their life satisfaction at 7 or above out of 10 .

\section{Figure 1 \\ GDP per head ${ }^{1}$ and life satisfaction ${ }^{2}$}

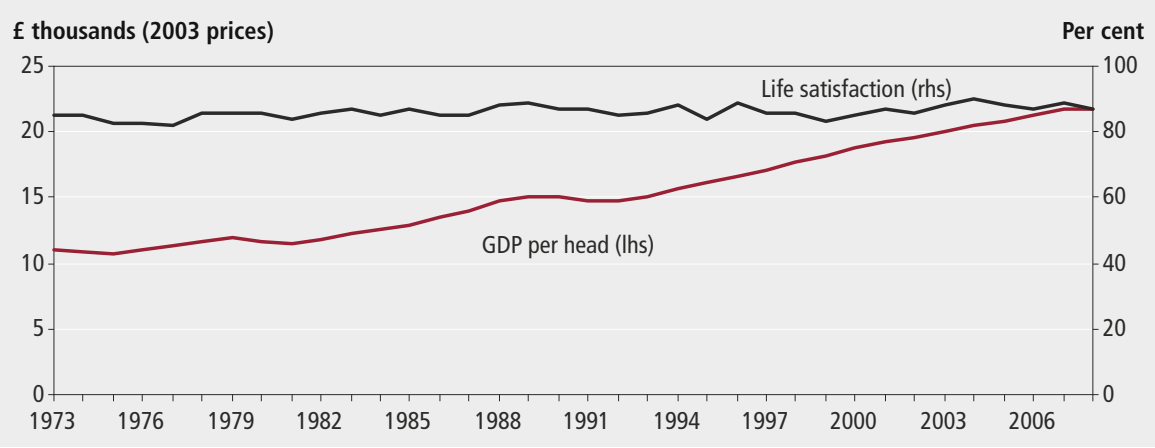

Notes:

Source: Eurobarometer (from World Database of Happiness), ONS

1 United Kingdom.

2 Life satisfaction data are as a proportion of Great Britain respondents who stated that they were fairly or very satisfied when answering the question: 'On the whole how satisfied are you with the life you lead?' - with the definitions 1 ) not at all satisfied; 2 ) not very satisfied; 3 ) fairly satisfied; 4) very satisfied. 


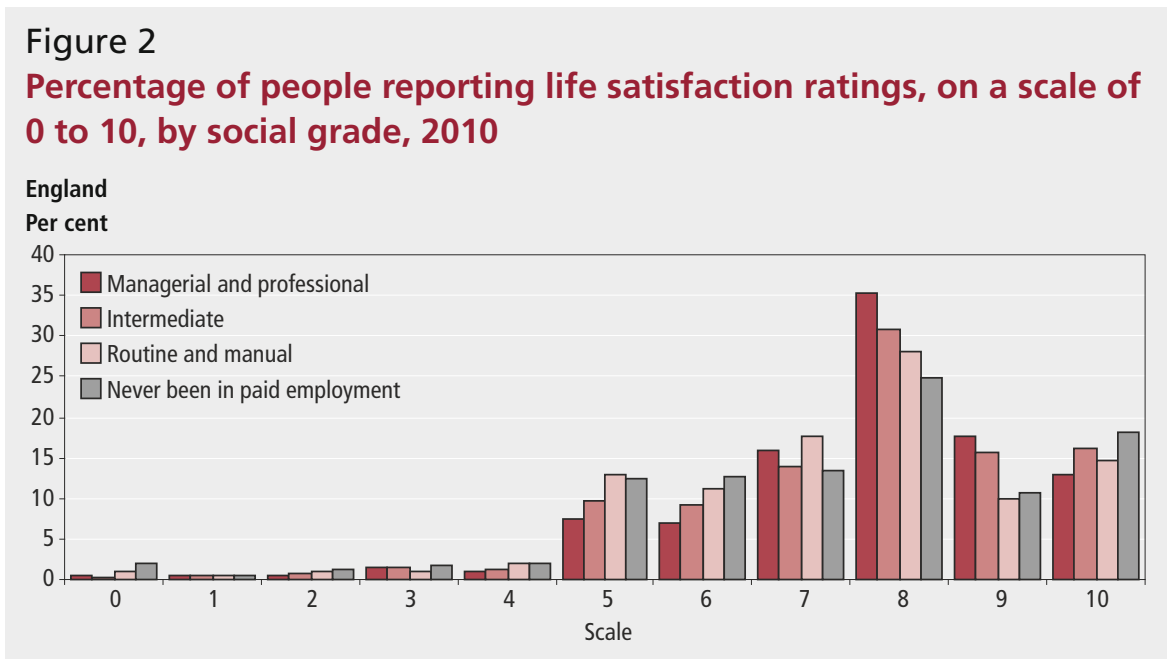

Source: Defra

As part of its project on measuring societal wellbeing, ONS is evaluating how subjective wellbeing is currently being measured by other surveys in the UK external to ONS and how these data are (or could be) used to inform policy (Waldron 2010).

\section{General challenges}

ONS has also produced a paper which looked at data sources available to help measure wellbeing against a variety of relevant domains $\mathrm{s}^{30}$. Whilst the domains differ to those used by the Stiglitz Commission report, the data sources identified offer a useful starting point for further work in this area. These data sources should provide a good starting point from which to select indicators, without the need to invent new ones.

ONS is conscious that domain and indicator selection are associated with a number of cross cutting challenges. These include the interrelationships between indicators, for example, the amount of daily exercise an individual undertakes has a direct impact on healthy life expectancy. In addition, the focus on the individual as opposed to society as a whole, and relative positions of those individuals in society are critical factors in the measurement of wellbeing. As such there is a body of literature on relative income, social comparisons and wellbeing (Clark and Senik 2010 and Blanchflower and Oswald 2004) which indicates that, if an individual is on a low income, living in an area where everyone else is on a low income it would impact their wellbeing to a lesser extent than if the same individual was living in a high income area.

Another point to note about low incomes is that the cross sectional relationship between life satisfaction and income indicates that additional income has a considerably bigger wellbeing benefit for people at the bottom of the income distribution than elsewhere. Other factors such as weighting, compensation and

\section{Table 2}

\section{Stiglitz Commission's quality of life dimensions with current activities and potential developments}

\begin{tabular}{l}
\hline Stiglitz Commission recommendation \\
\hline 6. Quality of life depends on people's objective conditions and \\
capabilities. Steps should be taken to improve measures of \\
people's health, education personal activities and environmental \\
conditions. In particular, substantial effort should be devoted to \\
developing and implementing robust, reliable measures of social \\
connections, political voice, and insecurity that can be shown to \\
predict life satisfaction \\
7. Quality-of-life indicators in all of the dimensions covered should \\
assess inequalities in a comprehensive way
\end{tabular}

8. Surveys should be designed to assess the links between various quality-of-life domains for each person, and this information should be used when designing policies in various fields.

9. Statistical offices should provide the information needed to aggregate across quality-of-life dimensions, allowing the construction of different indexes

10. Measures of both objective and subjective wellbeing provide key information about people's quality-of-life. Statistical offices should incorporate questions to capture people's life evaluations, hedonic experiences and priorities in their own survey.
Current activities and potential developments

Existing work:

Working papers to start to explore range of indicators.

Social capital work.

Social Trends.

Areas for development:

Continue to collaborate with stakeholders in the development of good relations, participation and influence and voice indicators.

Existing work:

Equalities Data Review (EDR) 2007 including the Equality Measurement Framework.

Focus On ... publications exploring dimensions of inequality (income, ethnicity, religion, gender, age).

Areas for development:

Continue to collaborate with stakeholders for equality related developments.

Existing work:

Research drawing on the ONS Longitudinal Survey and the ESRC-funded birth cohort and other longitudinal studies. Areas for development:

Investigate causality and conditions which determine the state of societal wellbeing.

Develop Time Use data.

Existing work:

GSS provides a wide range of social indicators.

Social Trends.

Areas for development:

Map all quality of life indicators, sources and societal wellbeing measures as the basis for proposing greater coordination in development and use.

Conduct an evaluation of existing measures (indicators and sources), identifying gaps and options for filling them. Investigate user requirements in the UK via a series of consultation events.

Investigate ways of weighting, for example by what people value/spend time on, and produce experimental weights.

Existing work:

Subjective wellbeing measured in survey used to compile one of the UK Sustainable Development Indicators (Defra) and measured in other Surveys (British Crime Survey and the Citizenship Survey).

Areas for development:

Include subjective wellbeing measures in core household surveys, with sample size large enough for local as well as national estimates.

Evaluate life satisfaction measures across wellbeing domains. 
Table 3

\section{Stiglitz Commission's quality of life dimensions with current activities and potential developments}

\begin{tabular}{|c|c|}
\hline Stiglitz Commission recommendation & Current activities and potential developments \\
\hline $\begin{array}{l}\text { 11. Sustainability assessment requires a well-identified dashboard } \\
\text { of indicators. The distinctive feature of the components of this } \\
\text { dashboard should be that they are interpretable as variations of } \\
\text { some underlying 'stocks'. A monetary index of sustainability has } \\
\text { its place in such a dashboard but, under the current state of the } \\
\text { art, it should remain essentially focused on economic aspects of } \\
\text { sustainability. }\end{array}$ & $\begin{array}{l}\text { Existing work: } \\
\text { Defra's sustainable development indicator set is recognised as leading edge. }\end{array}$ \\
\hline $\begin{array}{l}\text { 12. The environmental aspects of sustainability deserve a separate } \\
\text { follow-up based on a well-chosen set of physical indicators. In } \\
\text { particular there is a need for a clear indicator of our proximity to } \\
\text { dangerous levels of environmental damage (such as associated } \\
\text { with climate change or the depletion of fishing stocks). }\end{array}$ & $\begin{array}{l}\text { Existing work: } \\
\text { ONS regular publication of Environmental Accounts. } \\
\text { Areas for development. } \\
\text { Improve links between Environmental Accounts and measuring societal wellbeing work programme. } \\
\text { Investigate what other measures relevant to societal wellbeing would be beneficial in the Environmental Accounts. }\end{array}$ \\
\hline
\end{tabular}

Source: Office for National Statistics

\section{Figure 3 \\ GDP per head and the Happy Planet Index}

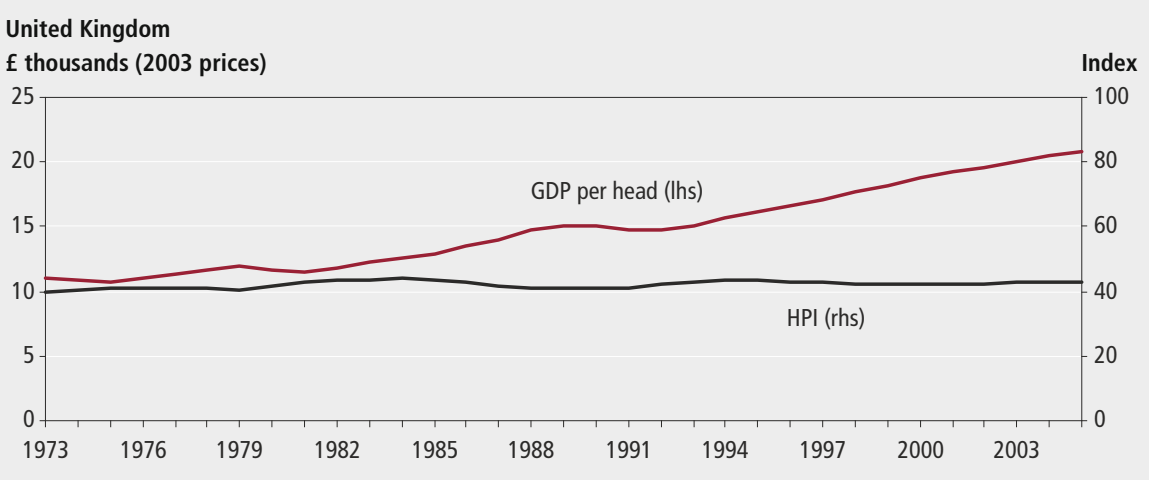

Source: ONS, New Economics Foundation

aggregation of indicators will also need to be considered in any robust approach to the measurement of societal wellbeing.

There are many sets of indicators that could be used to describe societal wellbeing in full or in part. However, none of these offer easy opportunities to produce a summary measure, for example by weighting indicators together or, for the statistical researcher, to undertake some kind of factor analysis.

Table 2 matches the Stiglitz Commission's quality of life dimensions with current activities and potential developments.

\section{Sustainability and the environment}

The Stiglitz Commission report highlights that the degradation of many natural resources such as emission of greenhouse gases is not included in the National Accounts. Rather, an increase in human wellbeing may have an adverse impact on the environment. For example, buying a car may make life for the consumer easier in the short term but what about the harmful emissions produced when the vehicle is in use? This coupled with the immediate concerns regarding environmental issues, particularly global warming, means that it is essential that sustainability and the environment are considered within the realm of societal wellbeing.

Figure 3 compares GDP in the UK with scores from the Happy Planet Index (HPI); an efficiency measure, showing wellbeing produced given units of resources used, based on life satisfaction, life expectancy and ecological footprint ${ }^{17}$. The HPI is designed as a simple indicator combining these three items, particularly to compare between countries. The chart shows that whilst GDP is increasing steadily the UK HPI score remains relatively stable over the same time period, perhaps indicating that GDP and other measures of progress move at different rates over time.

Significant developments have already been made in the identification of measures for sustainability and the environment, especially through Defra's set of 68 sustainable development indicators ${ }^{14}$ (incorporating a wellbeing subset), through which to review progress The indicators are updated annually. Each indicator is highlighted by a 'traffic light' that indicates the extent to which progress has been made.

In addition, ONS has been publishing Environmental Accounts since 2002 24 .
Environmental Accounts are 'satellite accounts' to the main National Accounts. The Environmental Accounts provide data on the environmental impact of UK economic activity, on the use of resources from the environment in the economy, and on associated taxes and subsidies. They are being compiled according to emerging international standards and should provide a strong platform on which to build. The Stiglitz Commission report refers to Environmental Economic Accounts as 'vital building blocks' for any form of sustainability indicators. For example, the Defra sustainable development indicators on climate change, which present changes in greenhouse gas emissions from specific industry sectors in the context of growth in economic output, are based on the Environmental Accounts.

The consultation document published by $\mathrm{ONS}^{31}$ in June 2010 outlines the strategy for strengthening the environmental accounts over the next three years and includes plans to strengthen the natural resource asset accounts.

Table 3 matches the Stiglitz Sustainability and the environment recommendations with current activities and potential developments.

\section{Conclusion}

Underpinning this article is the realisation that there is a host of useful information that already exists to help measure societal wellbeing in the UK. However, this is often not presented or recognised as helping to understand societal wellbeing. What is missing is a sense of coherence and how various constituent parts might 'add up' to a more complete measure. As a starting point ONS has developed a 'Wellbeing Knowledge Bank ${ }^{32}$ which is a repository of links, information and plans, to bring understanding and clarity to this subject area. 
With activities at all different levels of government, more strategic co-ordination across government should bring efficiency savings and reduce the burden on data providers, whilst recognising that decision making and resource allocation is the responsibility of designated authorities.

ONS has prepared an action plan, based on the Stiglitz Commission's recommendations, to identify those outputs where the recommendations are already, or could with relative ease, be met, all subject to resources being available. The plan sets out a way for ONS to progress the societal wellbeing agenda by working with others. ONS's general approach will be to exploit the wide range of existing outputs or planned developments (for example National Accounts and Social Trends) rather than developing extensive new outputs.

ONS, working with the rest of the GSS, has access to a wide array of data and statistical expertise and is well placed to take the societal wellbeing measurement agenda forward working with the Cabinet Office. ONS is also working with related developments on which the Government Economic Service and Government Social Research are leading, including the inclusion of social impacts in policy formulation, option appraisal and evaluation. Working with policy areas will ensure that requirements for better measures of wellbeing are soundly based.

We also aim to engage with a wide range of stakeholders and interested parties beyond central government, and with international organisations and other national statistical offices. For example, ONS will continue its international engagement with the OECD, UNECE and Eurostat work programmes. ONS is developing an engagement strategy that would look to exploit existing groups, networks and develop a programme of work via consultative events.

\section{Notes}

1. www.direct.gov.uk/en/Nl1/Newsroom/ Budget/Budget2010/DG_188496

2. 'Blueprint for a Green Economy' http://www.zacgoldsmith.com/default. asp? contentID $=29$

3. www.ted.com/talks/lang/eng/david cameron.html

4. www.beyond-gdp.eu/

5. www.oecd.org/document/13/0,3343,en _40033426_40037349_43005901_1_1_1 _1,00.html

6. www.oecd.org/ dataoecd/23/54/39558011.pdf

7. www.stiglitz-sen-fitoussi.fr/documents/ rapport_anglais.pdf
8. www.hm-treasury.gov.uk/d/hmt strategic_objectives_pu704.pdf

9. www.defra.gov.uk/sustainable/ government/documents/ Wellbeingresearchsynthesisreport.pdf

10. www.statistics.gov.uk/socialtrends/

11. www.statistics.gov.uk/pdfdir/wrk0307. pdf

12. www.statistics.gov.uk/StatBase/Product. asp?vlnk $=10336$

13. www.statistics.gov.uk/StatBase/Product. asp?vlnk $=15074$

14. www.defra.gov.uk/sustainable/ government/progress/data-resources/ sdiyp.htm

15. www.equalityhumanrights.com/ fairer-britain/equality-measurementframework/

16. www.youngfoundation.org/our-work/ local-innovation/strands/wellbeing/ wellbeing

17. www.happyplanetindex.org/

18. www.nationalaccountsofwellbeing.org/

19. This is despite GDP not being intended to be a measure of welfare. See for example Vanoli, 2005 for a discussion on the development of National Accounts.

20. www.statistics.gov.uk/statbase/product. asp?vlnk $=1143$

21. www.statistics.gov.uk/StatBase/Product. asp?vlnk $=242$

22. www.statistics.gov.uk/CCI/Nscl. asp? ID $=8244$

23. www.ons.gov.uk/about-statistics/ ukcemga/index.html

24. www.statistics.gov.uk/STATBASE/ Product.asp?vlnk=3698

25. www.statistics.gov.uk/hhsa/hhsa/index. html

26. www.ons.gov.uk/about-statistics/userguidance/sc-guide/index.html

27. www.culture.gov.uk/reference_library/ research_and_statistics/4828.aspx

28. www.statistics.gov.uk/statbase/Product. asp?vlnk $=9326$

29. www.timeuse.org/

30. www.statistics.gov.uk/downloads/ theme_social/Measuring-SocietalWellbeing.pdf

31. www.ons.gov.uk/about/consultations/ consultation-on-the-strategy-for-theuk-environmental-accounts/index.html

32. www.ons.gov.uk/about-statistics/ measuring-equality/index.html

\section{CONTACT}

elmr@ons.gsi.gov.uk

\section{REFERENCES}

Allin P (2007) 'Measuring societal wellbeing', Economic \& Labour Market Review vol 1, no
10, pp 46-52, available at: www.statistics.gov. uk/CCI/article.asp?ID=1882

Barnard A (2010) 'The effects of taxes and benefits on household income, 2008/09', available at: www.statistics.gov.uk/cci/article. asp? ID $=2440$

Blanchflower D and Oswald A (2004) 'Wellbeing over time in Britain and the USA' in Journal of Public Economics, vol 88, issue 7-8 pp 1359-1386

Chirpanhura (2010) 'Measures of economic activity and their implications for societal wellbeing', Economic \& Labour Market Review vol 4, no 7, pp 56-65, available at: www. statistics.gov.uk/cci/article.asp? ID =2469

\section{Clark A, Frijters P and Shileds M (2008)}

'Relative income, happiness, and utility: An explanation for the Easterlin Paradox and other puzzles', Journal of Economic Literature, vol 46, no 1, March 2008, pp 95-144(50)

Clark A and Senik C (2010) 'Who compares to whom? The anatomy of income comparisons in Europe', Economic Journal, 120 (May), 573-594

Daffin C (ed) (2010) 'Wealth in Great Britain: main results from the Wealth and Assets survey 2006/08' available at: www.statistics. gov.uk/downloads/theme_economy/ wealth-assets-2006-2008/Wealth_in_ GB_2006_2008.pdf

Gershuny J (2008) 'Time-use and the comprehensive accounting of social and economic activity', University of Oxford Sociology Working Papers 2008-03, available at: www.sociology.ox.ac.uk/documents/ working-papers/2008/2008-03.pdf

Gershuny J (2009) 'Activities, durations and the empirical estimation of utility', University of Oxford Sociology Working Papers 200907, available at: www.sociology.ox.ac.uk/ documents/working-papers/2009/2009-07. pdf

Krueger A, Kahneman D, Schkade D, Schwarz N and Stone A (2009) 'National Time Accounting: The Currency of Life', in AB Kreuger (ed), Measuring the Subjective Wellbeing of Nations: National Accounts of Time Use and Well-Being, University of Chicago Press/NBER, 2009, pp 9-81

Layard R (2005) 'Happiness: Lessons from a new science', Penguin: London

Vanoli A (2005) History of National Accounting, IOS Press: Amsterdam

Waldron S (2010) 'Measuring subjective wellbeing in the UK', available at: www.ons.gov.uk/about-statistics/measuringequality/wellbeing/understanding-wellbeing/ index.html 